\title{
BRASIL, COLÔMBIA, PERU E A DIVERSIDADE FRONTEIRIÇA ${ }^{1}$
}

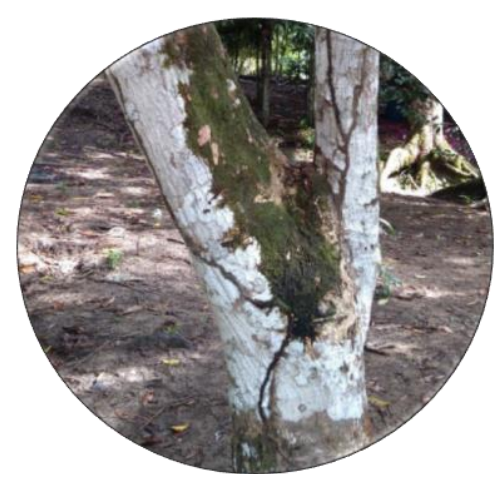

Michel Justamand

\begin{abstract}
Resumo
O artigo busca dialogar com mais de uma forma de pensar o mundo. Visa diálogos interdisciplinares em busca do entendimento da diversidade no Alto Solimões, na região de tríplice fronteira entre os países da América do Sul (Brasil, Colômbia e Peru). Contou-se nesses escritos com o conhecimento biológico, antropológico e social, para refletir sobre os entroncamentos disciplinares e em comunhão com a diversidade étnica, sociocultural, política e linguística.
\end{abstract}

Palavras-chave: Diversidade. Fronteira. Alto Solimões.

\begin{abstract}
The article seeks to dialogue with more than one way of thinking the world. It aims at interdisciplinary dialogues in search of the understanding of diversity in Alto Solimões, in the region of triple border between the countries of South America (Brazil, Colombia and Peru). These writings were written with biological, anthropological and social knowledge to reflect on the disciplinary connections and in communion with ethnic, socio-cultural, political and linguistic diversity.
\end{abstract}

Keywords: Diversity. Border. Alto Solimões.

${ }^{1}$ Esse texto teve a contribuição preciosa sobre questões ticuna de Josiane Otaviano Guilherme (Tutchiãüna). 


\section{Introduzindo a ideia}

Os hábitos têm relação com a cultura, segundo a ótica de quem escreve esse texto. Então as culturas construídas nos separam, mas acreditamos que podemos conviver harmonicamente mesmo com as diversas formas de ver, pensar e agir dos humanos no mundo.

Nosso objetivo é provocar os leitores, fazê-los refletirem novas formas de lidar com a diversidade, seja ela cultural e ou biológica. Acreditamos nas possibilidades de relações inter-multi-trans-poli disciplinares.

Para mostrar que é possível se fazer e desenvolver debates e construir pesquisas interdisciplinares farei uma correlação de ideias entre alguns acadêmicos, ativistas políticos e artistas com a produção do físico Henrique Lins de Barros. Por incrível que pareça, mesmo com toda a nossa dita "sabedoria" e conhecimento, estamos perdendo grande parte dessa riqueza por culpa do modelo de uso da natureza nos últimos anos pelas corporações e, muitas vezes, pelo estado. $\mathrm{Na}$ sua obra sobre a Biodiversidade, Barros delineia um extenso panorama sobre o atual equilíbrio do meio ambiente para mostrar como a sua deterioração ameaça de modo iminente a própria existência humana e, portanto, toda a sua produção cultural.

Por meio de uma luminosa síntese das principais teorias sobre o aparecimento e a evolução dos seres vivos, passando pela história da descoberta e da conquista das "novas terras", como as Américas, que expandiram os domínios ocidentais, dos estados europeus vencedores, França, Alemanha e Inglaterra, acrescidos dos EUA e Japão (responsáveis também pelo atual sistema, que nos referimos ao longo da escrita), Barros explica como a existência da vida no planeta depende de sua extrema 
diversidade, atualmente ameaçada pelo consumismo desenfreado e pela mentalidade de curto prazo da produção capitalista, com uma capa ou máscara que atualmente se conhece como neoliberal (JUSTAMAND, 2010).

\section{Biodiversidade e cultura}

O presente artigo tratará do entendimento de cultura e como isso se relaciona com a diversidade de construções culturais que a humanidade gerou ao longo da sua história e o que tem a sua disposição, especialmente voltada para a educação, formal ou informal. O conceito de cultura e toda a gama de suas nuances são muito usados nos escritos e discursos acadêmicos, nos antropológicos mais especialmente, desde as velhas 164 definições listadas por Kroeber e Kluckhohn (KUPER, 2002, 83).

As questões culturais estão presentes nas vidas de todas as pessoas desde quando os primeiros hominídeos desenvolveram seus instrumentos de pedra, quando modificaram as paisagens ao seu redor, ou ainda, quando construíram, constituíram e desenvolveram seus relacionamentos sociais.

Esses momentos ancestrais da construção da cultura humana são tão remotos que a memória individual não tem como os resgatar. São resgatados pela recordação dos mais antigos dos grupos ou com as investigações e intervenções da ciência, como as arqueológicas.

Já desenvolvi estudos com vestígios dos primeiros habitantes do país nos sítios arqueológicos de São Raimundo Nonato no Piauí. Nesse local a presença ancestral e suas atividades cotidianas ali praticadas podem ser reveladas, compreendidas e interpretadas (JUSTAMAND, 2015 a). 
Frisamos que nós, os humanos, somos uma das espécies mais frágeis fisicamente, mas mesmo dessa forma dominamos e "conquistamos" esse planeta, por estarmos em todas as partes, em muitas vezes de forma brutal exterminando espécies animais e vegetais (LEAKEY e LEWIN, 1995, 191). Mesmo sem ter asas voamos, sem ter guelras e ou membranas dominamos os mares. Tudo isso graças a tal da cultura, a produção de saberes, a acúmulos de conhecimentos e produções. A nossa cultura nos faz únicos, em alguns casos. Não que sejamos os únicos animais com cultura, ou com possibilidade de desenvolvê-la, mas por que com ela nos tornamos fortes, ágeis e dominamos os outros animais (infelizmente!).

A unidade de nossa espécie tem relação, por mais incrível que pareça, com a nossa diversidade de produções culturais espalhadas ao longo da história e do globo. Somos o resultado, em parte, de nosso meio, e também das nossas construções da cultura. É por meio dela que garantimos a transmissão de geração em geração, com ela participamos e partilhamos com os nossos pares. Herdamos de outros antes de nós um longo processo de criatividade e invenções para a construção, reconstrução e disseminação de nossas informações e saberes.

Dessa forma, adquirindo, ampliando, modificando muitas das vezes, mas sempre fazendo e ampliando sua cultura, os humanos passaram a depender cada vez mais do aprendizado, seja ele aquele institucionalizado “escolar" (formal e ou informal) ou com os nossos pares autodidatas, os conhecedores das tradições dos grupos sociais baseados em suas experiências adquiridas ao longo de suas vidas. Em muitas culturas humanas, esses conhecedores têm a incumbência de ajudar a transmitir de geração em geração os saberes acumulados pelo povo ou grupo. Eles têm muitos nomes educadores, mestres, pajés, entre outros. Podemos aprender 
de milhares de formas, métodos e em muitos lugares, não somente na sala de aula.

A cultura ajuda a compor as identidades dos grupos humanos em todos os locais, seja no passado distante ou hoje. Assim, nos parece, enquanto houver seres humanos na terra, serão forjadas novas identificações grupais, comunais, coletivas, muitas independentes, mas todas elas merecem viver.

Gersen Baniwa, liderança nacional indígena, defensor dos direitos dos índios em muitos espaços políticos brasileiros, representante indígena amazônico, conhecido e reconhecido, quando diz que são muitos os grupos indígenas espalhados pelo país e eles têm suas próprias formas de conceber a sociedade, a cosmologia, os valores e os contras valores, o que se considera valor e o que não (BANIWA, 2008, 67). A presença indígena no país deve ser considerada como constitutiva e participe da cultura nacional. Ainda há outros inúmeros grupos descritos como "minoritários" no país, que tem suas próprias formas de viver, como os quilombolas, ribeirinhos, ciganos, entre outros.

\section{Cultura para a ONU}

Partindo desse princípio para esse capítulo usaremos da definição de cultura aceita por organismos internacionais como a Organização das Nações Unidas - ONU. Para essa organização a Cultura, nesse momento com letra maiúscula, é a totalidade de normas, valores, crenças e tradições de uma determinada coletividade que porta uma identidade específica. Temos como exemplo o Alto Solimões, indígena, amazonense, tríplice fronteiriço com relações cotidianas com outros dois países Peru e Colômbia. Onde supomos, se vislumbra uma identidade social específica 
em relação a outras no país, mas em processo permanente de construção. Nessa região a identidade está muito mais marcada por características indígenas, por ser uma região ainda eminentemente composta por povos indígenas e seus descentes. Porém não podemos deixar de observar que existe a presença de outras contribuições como as das culturas negra e branca, que estão em relacionamento de permanente diálogo e se intercruzando.

Voltando a pensar na instituição multinacional ONU, que trata em suas muitas declarações, recomendações, debates e convenções aceita que é necessária outra forma de se agir, pensar e fazer no e para o mundo (BARROS, 2011, 2). Do mesmo modo, teríamos a chance de ter outro mundo onde caibam muitos mundos, biológico e humano, como lembra Richard Leakey (LEAKEY e LEWIN, 1997, 47), entre muitas outras etnias e com suas infinidades de culturas.

É preciso nos dar conta da enorme abrangência das produções culturais humanas. E incluir, agregar e juntar sempre, e não excluir, todas as culturas na grande Cultura Humana.

\section{A região do Alto Solimões}

Refletiremos, portanto aqui mais restritamente apenas a partir da região do Alto Solimões região da tríplice fronteira, Brasil, Colômbia e Peru. É formada por nove cidades brasileiras (Amaturá, Atalaia do Norte, Benjamin Constant, Fonte Boa, Jutaí, Santo Antonio do Iça, São Paulo de Olivença, Tabatinga e Tonantins); duas peruanas (Santa Rosa e Islândia) e uma colombiana (Letícia, capital de departamento) Há toda uma complexidade com suas muitas línguas indígenas, além do português e do espanhol. É uma mescla de diversas culturas nacionais, estaduais e 
municipais, dos encontros e desencontros dos que de fora vieram. Como no caso do Brasil,com a migração de nordestinos na época dos trabalhos voltados para a retirada da borracha.

Nessa região do país, muito rica culturalmente, temos contato com um número significativo de grupos indígenas: Ticuna, Marubo, Kaixana, Kambeba, Kanamari, Kokama, entre outros, havendo ainda os indígenas dos dois países vizinhos. Muitos representantes desses povos já passaram pelos bancos universitários da Universidade Federal do Amazonas - UFAM, em Benjamin Constant (JUSTAMAND, 2015b, 163). Esses estudantes vieram de muito mais de 10 etnias, também desses dois países vizinhos, Peru e Colômbia, que contribuem direta ou indiretamente na construção da "nuestra cultura", fronteiriça e tríplice. Estamos em diálogo permanente com todas essas culturas e formas diferentes de ver, agir e produzi-las e por isso estamos criando, construindo e ampliando as nossas relações. Nunca podemos nos esquecer da presença dos povos conhecidos como isolados, já que a vizinha Terra Indígena Vale do Javari (AM) abrigam muitos desses grupos entre os três países no mundo, lembrando que somente na Papua Nova Guiné há outros povos isolados. É desse caldeirão pluriétnico que pôde ser construída a identidade local, com suas nuances e especificidades com seu papel cultural no manejo do mundo graças aos seus saberes acumulados que são úteis a todo o mundo ${ }^{2}$.

Deveríamos ter a motivação para nos preocuparmos com a questão da cultura e demandarmos bens culturais produzidos mais próximos de nós, ou seja, que nós os compreendêssemos melhor e os utilizássemos de outro as formas. É preciso reconhecer e valorizar os conhecimentos tradicionais que também contribuem para o saber científico

${ }^{2}$ https://www.brasil247.com/pt/247/revista_oasis/163909/Sabedoriaind \%C3\%ADgena-O-que-os-povos-da-Amaz\%C3\%B4nia-sabem-e-n\%C3\%B3sn\%C3\%A3o-sabemos.htm, vista em 07/12/2015. 
para que as populações que desenvolveram tais saberes também recebam sua parcela nos louros (CUNHA, 2009, 309).

\section{A educação escolar e suas contribuições}

Parece-nos que até mesmo nas escolas, ou, aliás, principalmente nas escolas, encontramos várias formas/maneiras de intervenções culturais homogenizadoras no lugar da valorização da diversidade local, citamos como exemplo norteador os processos educacionais do Rio Negro (CABALZAR, 2012). Indicamos esse exemplo graças às inúmeras contribuições que acreditamos essas obras pode oferecer para se pensar o local amazônico e os seus usos na região do Alto Solimões.

Para citar apenas um caso típico de saber amazônico e ancestral dos indígenas o manejo da terra preta. Trata-se de uma técnica ancestralmente conhecida e desenvolvida pelos povos caçadores e coletores. Esses grupos que se deslocavam de acordo com as suas necessidades pelo ambiente, mas os seus depósitos seletivos recorrentes de múltiplas plantas transformaram os solos e gerou as terras pretas. Terras que são férteis e com características diferentes do solo que já existia na região e proporcionaram a criação de paisagens que relacionam o passado e o presente das sociedades do entorno. Esses resíduos e formações de terra são cobiçados pelos agricultores amazônicos de modo geral e também pela ciência, como a Empresa Brasileira de Agropecuária - EMBRAPA ${ }^{3}$. É importante lembrar que o papel dessa empresa tem sido se preocupar, sobretudo apenas com o setor agropecuário, deixando de lado o indígena e o dos povos tradicionais (CUNHA, 2009, 309). Esse saber/conhecer da

${ }^{3}$ https:// www.embrapa.br/busca-de-noticias/-/noticia/1493237/terra-pretade-indio-desperta-interesse-da-ciencia-internacional-; consultado dia 19/11/2015. 
terra preta é algo que deve ser reconhecido divulgado/estudado e apresentado com orgulho por ter sido desenvolvido pelos povos ancestrais da região amazônica.

Lembramos novamente dos escritos de Baniwa, quando trata da relação das escolas com os saberes indígenas. Para ele a escola é o cemitério da diversidade cultural, exatamente porque não promove a multiplicidade de saberes e conhecimentos, por que não os oferta (BANIWA, 2008, 70), ao menos não como prega em teoria a escola multicultural muito em uso no Brasil.

Voltando agora ao diálogo com a UNESCO, que produziu nos últimos anos diversos documentos com objetivo de promover e proteger a diversidade cultural dos povos que é preciso que se criem algumas precauções nas comunidades indígenas, mas também em outras locais. Especialmente contra as imposições veladas do sistema mundo, lembradas por Immanuel Wallerstein desde os anos 70 do século passado e das grandes corporações capitalistas, evidentemente, buscando manter o respeito às questões culturais. Por esses motivos, esse organismo tem realizado e promovido a maior quantidade regulamentações e dispositivos normativos, visando garantir, ao menos em parte, a sobrevivência da cultura de cada localidade em detrimento da força da cultura hegemônica imposta por corporações a todos os recantos do mundo. Como mostra o parágrafo 46 do Relatório da Comissão Mundial sobre Meio Ambiente e Desenvolvimento da $\mathrm{ONU}$ ao indicar que os povos indígenas e tribais precisarão de atenção especial diante das ameaças trazidas pelas forças do desenvolvimento econômico a seus modos de vida - modos de vidas esses que podem oferecer às sociedades modernas muitas lições de manejo de recursos em complexos ecossistemas de floresta, montanha, e zonas áridas (CUNHA, 2009, 318-9). Condição que se sente até mesmo no Alto 
Solimões/AM, onde muitos achavam que estavam protegidos graças a seus relativos isolamentos geográficos.

Outro exemplo de espaço amazônico é o Rio Negro, ali se desenvolvem formas de manejar a região e de como lidar com o meio que podem ser usadas por todos (CABALZAR, 2010). O Alto Solimões tem ainda muito a experimentar e também a oferecer, graças a sua diversidade cultural.

Existe ainda outro saber tradicional que une as regiões amazônicas fronteiriças, entre Brasil, Peru e Colômbia, do lado brasileiro desde o estado de Rondônia e todo o leste do Acre até o noroeste do estado do Amazonas: o da produção da ayahuasca. Bebida fermentada adotada em espaços religiosos tradicionais de toda essa região (CUNHA, 2009, 314). A ayahuasca mostra como são diversas as relações de usos e costumes culturais muito imbricadas entre os saberes, as regiões, as populações e o meio ambiente.

\section{Preocupações nacionais}

No Brasil, a questão da diversidade cultural está relacionada no sentido de quem tem e usa-a, entre outros aspectos, com as diferenças sociais, mas especialmente com as desigualdades socioeconômicas. É preciso notar e se preocupar que em terras tupiniquins quem perderá com as imposições sistêmicas são os mais necessitados na promoção de seus bens culturais, sejam eles materiais e ou imateriais.

Entre os que perderão mais estão os conhecimentos tradicionais e ancestrais de ciganos, indígenas, quilombolas e ribeirinhos, entre outras 
comunidades pequenas que dificilmente terão seus direitos e seus saberes preservados.

Algumas perdas de conhecimentos inestimáveis podem se tornar irrecuperáveis pelas populações locais, como são os mais variados saberes tradicionais, a exemplo da vacina do sapo (CUNHA, 2009, 315). Talvez somente com ações e interferências governamentais de defesa desses direitos e com a preservação deles pelas comunidades locais, haja a sobrevivência ainda das tradições, saberes e conhecimentos.

Com uma postura governamental de proteção esses grupos mais vulneráveis dentro do país podem ter seus conhecimentos ancestrais mantidos e preservados para serem usados e repassados. É nesse caso que entram os professores/educadores ${ }^{4}$, por exemplo, das escolas das regiões onde há enorme diversidade cultural, como é o caso da região do Alto Solimões e da Tríplice Fronteira. Para que não sejam as escolas cemitérios como descreve Baniwa. É preciso que sejam as escolas que virem a existir sejam as da luta. Luta por outro espaço de conhecimentos e saberes que valorizem também o que é local e não só as belas roupas vindas de fora, por que algumas dessas belezas trazem em si germes do capitalismo e doenças. Como escreveu Paulo Freire é do local que se parte para o internacional e depois de volta para o local, frase frequentemente atribuída ao autor.

${ }^{4}$ Entende-se por educadores, nesse artigo, pessoas que estão preocupadas com a vida como um todo dos educandos. Não somente com a presença, nota e em repassar conteúdos, muitas vezes descontextualizados da realidade local. Temos como indicador terminológico a concepção freiriana de que o educador "ensina os conteúdos de sua disciplina com rigor e com rigor cobra a produção dos educandos, mas não esconde a sua opção política na neutralidade impossível de seu que fazer" (2000, p. 44). Ver também em A importância da educação na fronteira. JUSTAMAND, Michel, 2012, p. 67. 


\section{A questão para os educadores, cultura tradicional e trabalhos em sala}

Os educadores precisam se preocupar mais com suas metodologias de ensino e em aceitar o novo, o diferente e não somente textos formulados pelas editoras e governos e enviados às escolas em forma de livros didáticos, ou outros materiais com a mesma intenção "dita didática", mas que na prática é mais alienadora possível. Criem seus próprios materiais, textos, metodologias e avaliações, já apontamos isso antes em outro trabalho, é possível educar e avaliar de outras formas (JUSTAMAND, 2009).

Os educadores precisam se preocupar também com as propostas curriculares e com as suas próprias. As propostas de currículo vindas de fora geralmente não atendem as necessidades locais, nem sabem que existem outras demandas, sabem apenas daquelas impostas por um sistema de ensino que mais brutaliza e coisifica do que educa.

Os professores/educadores, segundo nosso olhar, têm a nobre incumbência de ir além das regras, ditames e diretrizes impostas pelos órgãos oficiais e valorizar os saberes locais.

Temos a Constituição de 1988, em vigor e a nosso favor, pois ela protege os professores no artigo 206, que versa sobre a liberdade de escolher a metodologia, a forma de avaliar e os conteúdos.

Assim, é preciso permitir que esses saberes regionais sejam, também, participes nas aulas. Saberes acumulados ao longo de milhares de anos e que devem ter, em muitas vezes, o seu devido valor dado em sala de aula e ou nos espaços que forem usados para o fim de gerar a troca de saberes. Tomamos aqui emprestado os conhecimentos já divulgados por um projeto desenvolvido na região do Rio Negro, de escrever uma história 
ancestral da região, quando trata do conhecimento e lugares (ANDRELLO, 2012).

No Alto Solimões poderíamos também realizar esse trabalho de resgate da história mais antiga e que ela seja divulgada. Como os Ticuna já têm feito no Museu Magüta, no qual divulgam sua narrativa histórica e os seus conhecimentos acumulados na cidade de Benjamin Constant. Dessa forma, as aulas e seus espaços de interação serão mais valorizados pelos educandos que certamente, renderão muito mais em seus afazeres nas escolas e na vida. Recomendamos que esse espaço museológico Ticuna fosse frequentado por todos os moradores da região. Ele pode servir de exemplo para futuras conquistas dos outros povos e grupos do Alto Solimões, mas não só, a luta para a conquista desse espaço sociocultural, pode servir de modelo exemplar para muitos outros povos e grupos sociais.

Com tais práticas oferecemos experiências inovadoras e constitutivas para novos olhares e saberes nas escolas. Nunca esquecendo que partimos de compreender o local para o internacional. É com os desejos, saberes, interesses e vontades locais que se parte para os conhecimentos internacionais, e se troca com eles, para voltar para o local com outros olhares sobre as questões ali existentes, aquelas que nos são mais próximas.

Para os educadores, deixamos o recado de buscar ampliar os relacionamentos com as diversas organizações sociais locais e com os grupos de representação e quem sabe também de ativismo político para as devidas pressões nas questões sociopolíticas (BARROS, 2011, 5) de cada região. No Alto Solimões, por exemplo, há organizações de professores 
indígenas ${ }^{5}$ atuantes nas cidades de Atalaia do Norte, Benjamin Constant, Tabatinga, e que provavelmente, devem atuar em outros municípios também. Não é, de modo algum, constrangedor para qualquer educador estreitar esses diálogos interinstitucionais. Esses diálogos com certeza levarão a resultados completamente inesperados e que podem proporcionar a valorização dos saberes do local.

Deve ser preservado, mantido e debatido o que há de mais original, tradicional e ou nascido em cada região e somente com os diálogos com as diversas formas de cultura externas é que ganharemos como sociedade, nossa construção e apresentação para o maior número de participes, preferencialmente. Ou seja, caso tenhamos outra forma de relacionamento com a cultura local, seremos em breve uma nação com nossos vínculos tradicionais, ancestrais, imemoriais, coletivos e com suas identidades mais valorizadas.

Esse tipo de atitude pode e deve começar nas também nas escolas, para que elas não sejam realmente cemitérios. Sabemos que existem outros espaços políticos, sociais e culturais que contribuem para a construção e dinamização de aspectos socioculturais para a vida de todas e todos.

A cultura tradicional e ou popular seria um conjunto de criações de uma comunidade fundada, muitas vezes, na tradição, e expressas por um grupo ou por indivíduos e que, reconhecidamente, respondem às expectativas de sua identidade cultural e social da comunidade (IDEM, 6).Partindo desse pressuposto, os educadores devem buscar em suas aulas na região possibilitar o transbordamento dos saberes locais em possível intercâmbio com o que vem de outras partes.

${ }^{5}$ Temos como exemplo a mente a Organização Geral dos Professores Ticuna Bilíngües (OGPTB). 
Para nós, professores/educadores é fundamental essa ação na região amazônica. Salientamos também a importância de conhecermos mais a cerca da diversidade biológica (plantas e animais), pois sem dúvidas, tal diversidade proporcionou também uma enorme gama de adequações humanas. Adaptações que consequentemente nos legaram informações sobre como pode será vida no local fruto de conhecimentos constituídos ao longo dos milhares de anos. Esses que são importantes para ajudar a compreender de diferentes modos o mundo. Não se pode desprezar tais noções e deixar de incorporá-las nas aulas.

\section{Posicionamentos externos}

Voltamos as nossas preocupações internacionais e seus devidos relacionamentos. A Conferência Intergovernamental sobre Políticas Culturais para o Desenvolvimento, realizada em Estocolmo, em 1988, defende que deva existir uma preocupação mundial com a diversidade cultural, assim como já há para com a diversidade biológica (IDEM). No Alto Solimões, onde temos, em imensa quantidade, tanto diversidade biológica quanto variedade sociocultural, expressa nas múltiplas línguas faladas na região. Acreditamos que a preocupação local é maior para conhecer e reconhecer esses patrimônios da localidade.

Barros lembra que a maior riqueza que temos como humanidade nesse século é a espantosa diversidade de formas vivas e suas relações complexas. Como nossa diversidade sociocultural no Alto Solimões. Tal riqueza é muito superior ao que se pode imaginar. O autor ressalta ainda que graças à diversidade biológica, somos capazes de nos adaptarmos à mais diversas situações (IDEM, 12/17/19).

Não podemos nunca nos esquecer de que a diversidade, tanto a biológica quanto a cultural, são bens inestimáveis e inquestionáveis. Bens 
que não são passíveis de valorar. Para Barros são incompatíveis com as visões econômicas (IDEM, 24).

Portanto, é preciso salvaguardar a diversidade, a cultura tradicional e popular e o patrimônio imaterial dos interesses vantajosos das chamadas indústrias culturais (IDEM, 7). Organismos que estão preocupados, única e exclusivamente, com os lucros e faria em nome de tal lucro tudo o que for possível. Passar por cima, literalmente, dos interesses locais, com certeza. Chomsky lembra que os EUA já o fizeram inúmeras vezes ontem e hoje, em muitas partes da terra, em os Banhos de Sangue (CHOMSKY e HERMAN, 1976).

O patrimônio cultural imaterial tem sofrido "assaltos", sequestros, roubos, tanto quanto os patrimônios materiais. Porque o imaterial não se pode pegá-lo, não é físico, palpável tais como tradições e expressões orais, incluindo o idioma, expressões artísticas, práticas sociais, ritos e atos festivos, conhecimentos e práticas relacionadas à natureza e ao universo, técnicas artesanais tradicionais e a medicina tradicional (BARROS, 2011, 7).

Parece-nos que é importante valorizar os mestres de artes, em suas mais variadas formas. Pois são considerados portadores dos saberes, dos afazeres, das memórias orais, das celebrações. Assegurar que esses mestres tenham acesso e condições de transmissão de seus conhecimentos para as futuras gerações pode ser um caminho para estabelecermos novos relacionamentos educacionais, onde todos teriam vantagens.

Tal metodologia de troca com mestres tradicionais pode ocorrer nas escolas com a sua presença pessoal, ainda mais na região amazônica, onde muitos vivem bem próximo a essas instituições formais. 
Assim, se torna imprescindível valorizar, respeitar, conhecer melhor, reconhecer e divulgar a importância dessas tradições, dos mestres locais e de suas posturas e políticas ideológicas.

Pensamos que é imprescindível valorar a diversidade cultural que passou a ter importância a ponto de mobilizar o mundo. Um valor com condições de catalisar e municiar grupos político-culturais em todo o mundo, como as coalizões globais têm demonstrado (IDEM, 9).

Recorremos novamente à interpretação e à relação com os organismos internacionais, para de alguma forma referenciar nossas opções ideológicas. Segundo a UNESCO todas as culturas têm o direito de serem o que são, ou seja, de manterem seus costumes, tradições e crenças. E essas mesmas culturas têm também o direito de adquirirem novos hábitos, sempre lembrando, desde que desejem partilhar os outros e os seus costumes e tradições (IDEM).

Deste modo, luta-se contra a homogeneização, as estandardizações dos universos simbólicos e dos códigos identitários, em impostos sistemicamente.

Elencamos a seguir algumas sugestões imprescindíveis visando a dinamização das relações culturais, tendo em vista a importância desses aspectos para a vida humana. De tal modo entendemos que:

1 - a cultura ajuda a compor as identidades dos grupos humanos;

2 - a diversidade cultural está diretamente relacionada com as diferenças sociais, econômicas e políticas;

3 - é importante ampliar o relacionamento com as diversas organizações sociais locais; 
4 - é importante buscar preservar, manter e debater, os saberes e conhecimentos originais, tradicionais e locais;

5 - devem-se ter preocupações com a diversidade cultural, assim como há com a diversidade biológica; e

6- valorizar os mestres de todas as artes, os “artesãos” fazedores da cotidianidade local.

Não podemos deixar de escrever que os processos culturais são e estão numa constante construção, não há cultura parada. A cultura é dinâmica, é como a entendemos nesses escritos. É importante que todos tenham clareza de que nem todos os povos do planeta acompanham as mesmas estruturas, ditames, regulamentações e proposições. Há, sem dúvida, outros modos de agir, desejos, interesses e valores. Por isso talvez existam tantas definições de cultura quanto àquelas elencadas pelos antropólogos.

Barros lembra ainda que, o maior desafio humano é pensar uma nova relação com o meio ambiente, caso contrário, não parece impossível que estejamos ingressando em um período crítico de escassez de elementos vitais como a água e o ar (IDEM, p. 33).

Os grupos locais e tradicionais têm exemplos a ensinar acerca de suas realizações, adaptações ao meio ambiente. São saberes ou "construções" culturais que podem, em determinados momentos, oferecer apoio para outros grupos sociais que vivem na mesma localidade. Mas tais construções podem, ainda, servir a outros povos que vivem em outros locais e mesmo de outras épocas. Como é o exemplo da terra preta já citada acima como o conhecimento da vacina de sapo por diversos grupos no Acre (CUNHA, 2009) e de inúmeros saberes como a produção da pasta de dente e da cerveja feitas pelos Ticuna, no Alto Solimões. 
Infelizmente sabemos que o intercâmbio cultural regional não é valorizado como devia, por esse motivo também nos insurgimos e lembramos que é muitíssimo importante valorar esses diálogos regionais. Esse fato de não se valorizar os saberes regionais se deve ao fato de servem tratados como incapazes de produzirem trabalhos acadêmicos. A educação formal deve ir à contramão desse posicionamento, seja de quem for, e tentar prezar e preservar a diversidade cultural. Evidentemente respeitando e mantendo os conhecimentos, inovações e práticas das comunidades locais, exatamente como é preconizado na Convenção sobre Diversidade Biológica de 1992, em seu artigo 8. Convenção que tem mais de 200 países signatários, entre eles o Brasil (CUNHA, 2009, 323).

Não podemos deixar de informar que os conhecimentos indígenas e tradicionais são tantos que, obviamente, apenas um artigo seria pouco para enumerar tanta sabedoria já herdada pelo povo brasileiro.

Alguns desses exemplos de como lidar com o meio ambiente poderiam ser explorados pedagogicamente em salas de aula pelos educadores, a partir de relações com os conhecimentos dos mestres locais. Para Barros não existe nenhum organismo vivo que consiga se manter, sem ter relações permanentes com o meio onde está inserido (BARROS, 2011, 53). Por esse motivo, pensamos que há necessidade de relações da escola com o seu entorno, e que é necessário amplificar os diálogos e interações dos educadores com outras instituições além da escola.

\section{Concluindo finalmente, mas sem resolver o problema!}

O lucro não pode ser o objetivo final da lógica dos humanos (IDEM, p. 83). Não podemos aceitar tal situação de forma passiva. Pensamos que é importante mudar os pontos de vista, encarar novas 
formas de ver, pensar e agir. Não é necessário sermos permanentemente submissos, obedientes, ordeiros...! É possível soltar as amarras que nos prendem e sufocam!

Assim, nas escolas será preciso ver, ouvir, conhecer, reconhecer, aceitar, respeitar, outras formas de fazer e viver a vida no mundo. Outros modelos de vida são possíveis e estão em atividade ainda, por incrível que pareça existem grupos indígenas isolados com pouquíssimo contato com o mundo externo. Muitos desses grupos vivem na região dessa tríplice fronteira, desenvolvendo quem sabe outros conhecimentos, como a terra preta, para o futuro de todos. Há a presença de outros grupos como esses em outros locais do país e do continente. Eles são um exemplo de como se relacionar com o meio ambiente.

Há também tantos outros grupos indígenas, ribeirinhos, quilombolas, ciganos, que têm seu modo de vida para oferecer. É interessante conhecê-los melhor e, com certeza, valorizá-los devidamente a fim de identificá-los e apresentá-los nas escolas da região para termos outras formas de pensar as relações humanas no Alto Solimões, pensar e aprender da localidade para com o mundo. Pensamos que essa reflexão é dever de todas e todos os educadores!

Podemos sim ter outro mundo, um mundo onde caibam muitos mundos, como lembram os zapatistas (além do já citado Leakey), na voz do seu subcomandante, dissidente e mascarado, Marcos, representando a assembleia indígena na luta desarmada do Exército Zapatista de Libertação Nacional - EZLN contra as forças sistêmicas do mundo global, interessadas somente nos lucros que a região mexicana oferece e não nos saberes, conhecimentos e povos que ali vivem. Em comum, lembramos que o movimento zapatista está baseado no sudoeste mexicano, região de fronteira e de selva, como a do Alto Solimões (JUSTAMAND, 2012, p. 72). 
Para concluir citaremos reflexão feita pelo cantor, músico, poeta, artista, militante do movimento negro, o ex-Ministro da Cultura no Brasil, Gilberto Gil sobre o significado de cultura no nosso país. Essa poderia ser outra definição de cultura e contribuir para outros espaços mundo.

A cultura funciona como uma dimensão simbólica da existência social de cada povo, argamassa indispensável a qualquer projeto de nação. Cultura é um eixo construtor das identidades, um espaço privilegiado de realização da cidadania e da inclusão social e, ainda, como fator econômico gerador de riquezas (GIL, 2003).

\section{Referências}

ANDRELLO, Geraldo (org.). Rotas de Criação e transformação: narrativas de origem dos povos indígenas do Rio Negro. São Paulo: Instituto Socioambiental ISA; São Gabriel da Cachoeira, AM: Federação das Organizações Indígenas do Rio Negro - FORN, 2012.

BANIWA, Gersem. Diversidade Cultural, educação e a questão indígena. In: BARROS, José Márcio (org.). Diversidade Cultural: da proteção à promoção. Belo Horizonte: 2008.

BARROS, Henrique Lins de. Biodiversidade em questão. São Paulo: Cia. das Letras, 2011.

CABALZAR, Flora Dias (org.). Educação escolar indígena do Rio Negro, 19982011. Relatos de experiências e lições aprendidas. São Paulo: Instituto Socioambiental - ISA; São Gabriel da Cachoeira, AM: Federação das Organizações Indígenas do Rio Negro - FORN, 2012.

CABALZAR, Aloisio (org.). Manejo do Mundo: conbecimentos e práticas dos povos indígenas do Rio Negro, noroeste amaz̧ônico. São Paulo: Instituto Socioambiental - ISA; São Gabriel da Cachoeira, AM: Federação das Organizações Indígenas do Rio Negro - FORN, 2010.

CHOMSKY, Noam e HERMAN, E. Banhos de Sangue. Trad. Maria do Carmo Pizarro. São Paulo/Rio de Janeiro: Difel, 1976.

CUNHA, Manuela Carneiro da. Cultura com aspas. São Paulo: Cosac Naify, 2009. 
FREIRE, Paulo. Pedagogia da indignação: cartas pedagógicas a outros escritos. São Paulo: UNESP, 2000.

GIL, Gilberto. Pronunciamento na Comissão de Educação, Cultura e Desporto da Câmara dos Deputados. Em 14/05/2003.

JUSTAMAND, Michel. Educação por meio de atividades avaliativas. Porto Alegre: Deriva, 2009.

JUSTAMAND, Michel. Neoliberalismo: a máscara atual do capital. Rio de Janeiro: Achiamé, 2010.

JUSTAMAND, Michel. A importância da educação na fronteira. In: JUSTAMAND, Michel e RODRIGUES, Gilse Elisa (orgs.). Fazendo Antropologia no Alto Solimões. Embu das Artes: Alexa Cultural, 2012.

JUSTAMAND, Michel. O Brasil desconhecido: as pinturas rupestres de São Raimundo Nonato, Piauí. Embu das Artes: Alexa Cultural, 2015 a.

JUSTAMAND, Michel. Uma pequena e breve contribuição para os debates Antropológicos no Brasil: algumas experiências de Benjamin Constant. In: JUSTAMAND, Michel e SILVA, Adailton da. Fazendo Antropologia no Alto Solimões 2. Embu das Artes: Alexa Cultural, 2015 b.

KUPER, Adam. Cultura: a visão dos antropólogos. Trad. Mirtes Frange de Oliveira Pinheiros. Bauru: EdUSC, 2002.

LEAKEY, Richard e LEWIN, Roger. La sexta extincion. El futuro de la vida y de la humanidad. Trad. Antonio-Prometeo Moya. Barcelona: Tusquets, 1997. 